\title{
Improving Resistance to Moisture Damage of Asphalt Concrete Using Bamboo Ash as Void Filler
}

\author{
Gloria G. George ${ }^{1 *}$, Emmanuel O. Ekwulo ${ }^{2}$, Enwuso A. Igwe \\ ${ }^{I}$ Department of Civil Engineering, Rivers State University, Port Harcourt, Rivers State, Nigeria. \\ ${ }^{2}$ Department of Civil Engineering, Rivers State University, Port Harcourt, Rivers State, Nigeria \\ ${ }^{3}$ Department of Civil Engineering, Rivers State University, Port Harcourt, Rivers State, Nigeria
}

*Corresponding Author: Gloria G. George, 1Department of Civil Engineering, Rivers State University, Port Harcourt, Rivers State, Nigeria

\begin{abstract}
Mineral and organic fillers used in asphalt concrete production are vital in the performance of flexible pavements, hence, numerous mineral fillers are currently being used to improve the quality of asphalt concrete mixes. In this research, laboratory investigations on asphalt concrete mixes were carried out to determine the contribution of Bamboo Ash as filler, to the Stability and resistance to moisture damage of Hot Mix Asphalt (HMA) concrete under submerged conditions; Marshall Stability, Retained Marshall Stability (RMS), Swell and Swelling index (SI) of asphalt mixes at 0, 1, 2, 3, 4, and 5\% void filler content were investigated. For the purpose of this research, unmodified and Bamboo Ash-modified asphalt specimens were prepared and soaked for 0 to 5days, the 0 day representing unsoaked/dry specimen. Stability values of the specimens were obtained and the Retained Marshal Stability determined. Swell and Swelling Index (SI) of unmodified and modified specimens soaked for 0 to 5 days were also determined. The research showed that Bamboo Ash used as filler improved the Stability and Retained Marshall Stability of the asphalt concrete mixes at 3\% optimum filler content. The result also indicated that Bamboo Ash used as filler improved resistance to moisture damage with a reduction in Swell and Swelling Index to a minimum at 3\% filler content. The research concluded that Bamboo Ash is capable of reducing loss in Stability, and increasing resistance to moisture damage in Asphalt concrete mixes, and recommended that Bamboo Ash at 3\% filler content be used in production of asphalt concrete.
\end{abstract}

Keywords: Moisture Damage, Asphaltic Concrete, Bamboo Ash, Void Filler, Stability, Swelling Index

\section{INTRODUCTION}

Hot Mix Asphalt (HMA) concrete mix design is a process to ascertain appropriate proportion of materials to produce suitable and long lasting performance pave mixture during its service life. This is a composition of binder, coarse and fine aggregates, in different relative proportions to determine the strength and physical properties of the mix and the performance of the mix as a finished flexible pavement. The design of asphalt paving mixes is a huge issue in selecting and proportioning the material contents, in order to optimize all the expected results.

The role of fillers in hot mix asphaltic concrete is essential and vital in improving its engineering properties especially in flexible pavements. Various studies and investigations have shown that properties of void fillers have significant effect on the capabilities of asphalt concrete pavements. Exploration and studies have shown that characteristics of asphalt binder and aggregates, traffic conditions and climates are the principal factors that contribute to premature pavement failures [1].

As a result, void fillers have been incorporated into roadway specifications; this has promoted greater use of the materials

Environmental factors such as temperature, air and water can have intense effect on the strength and affect the amount of moisture damage which occurs in asphalt concrete mixtures. Some of these factors are associated to the materials that make-up hot mix asphalt (HMA) such as aggregate and bitumen. The factors related to mixture design and constructions are air void level, asphalt thickness, permeability and drainage. To improve or to control the deformations due to moisture damage, various researches were performed and in this research, bamboo ash as void filler showed good 
performance with bitumen resulting in some of the favorable properties in terms of strength. . In this research, the properties of asphaltic concrete mixes modified using Bamboo Ash as void filler was assessed. The moisture resistance characteristics of the modified asphalt concrete mixture was evaluated using results of Marshall Stability and Swelling Index.

\section{MATERials AND Methods}

\subsection{Sample Collection}

The materials used for this research includes fine and coarse aggregates, bitumen, and void filler. The fine aggregate used was sharp sand, while the coarse aggregates were graded granite chippings. The sharp sand and granite chippings were obtained from the local building materials market at Mile-3, Diobu, Port Harcourt, Rivers State, Nigeria. The bitumen was obtained from Julius Berger construction company, Port Harcourt, Rivers State, Nigeria. The filler used was Bamboo Ash (BA), the Bamboo was obtained from the local building materials market at Mile-3, Diobu, Port Harcourt, Rivers State, Nigeria. Bamboo Ash is an organic material resulting from the mechanical powdering of Bamboo into fine powder. The ash was obtained by incineration and has a specific gravity of 1.86 . It was then dry sieved through $75 \mu \mathrm{m}$ sieve.

\subsection{Material Properties and Classification Tests}

The properties of the bitumen, aggregates and the Bamboo Ash were determined using standard procedures. The technique used in attaining the outcome of this research comprised of classification of materials used; aggregates and bitumen. The specific gravity and classification tests of bitumen such as viscosity, penetration, softening point and penetration were also determined.

\subsection{Sampling Preparation}

The asphalt concrete briquette samples used for this study were prepared in accordance with the guidelines as stated by Bruce Marshal for Mix Design Procedures as presented in [2], [3], [4] and [5]. The mix design proportion consisted of coarse aggregates, fine aggregates and mineral filler. The gradation test was carried out according to [6].

The asphaltic concrete briquette samples were prepared as per [7] at different bitumen contents to obtain the optimum bitumen content (OBC) of $4.5 \%$. This OBC was used for the preparation of specimen briquettes for the control mix at $0 \%$ and the modified mixes. The briquettes were prepared by addition of Bamboo Ash at 1, 2, 3, 4 and $5 \%$ by weight of the control mix and submerged in water for 0 to 5 days ( 0 day represents the dry and unsoaked specimens).

The Compacted briquette samples were subjected to bulk specific gravity test. Additional briquette samples were prepared and placed under submerged conditions. Subsequently, on each day of curing, samples were crushed using the Marshall Test apparatus and subjected to stability, flow, density and void analysis at a temperature of $600 \mathrm{C}$. Also, the weight in air and weight in water values were obtained and recorded.

The durability properties determined under submerged conditions include; Marshall Stability, Retained Marshall Stability (RMS), Swell and Swelling Index (SI).

\subsection{Marshall Stability and Retained Marshall Stability}

Marshall Stability measures the maximum load sustained by the asphalt material at a loading rate of $50.8 \mathrm{~mm} /$ minute. It is the performance prediction measure conducted on asphalt concrete mixes. The Marshall Stability test procedure consists of determination of the properties of the mix, Marshall Stability, flow analysis and optimum binder content.

The index of Retained Marshall Stability (RMS) can be defined as the stability retained by the sample after it must have been submerged in water over a stipulated period. RMS can be used to measure the resistance to moisture damage of the mix being tested [8]. Index of retained Marshall Stability (RMS) is the ratio of Stability of immersed specimen to the Stability of dry specimen and expressed as percentage as presented in equation (1)

$R M S=\frac{S_{1}}{S_{0}} \times 100$ 
Where;

RMS = Retained Marshal Stability

$\mathrm{S}_{1}=$ Stability after immersion of sample

$\mathrm{S}_{0}=$ Stability before immersion of sample

\subsection{Swell and Swelling Index}

Swell is the increase in volume as a result of absorption of water by asphalt concrete when submerged in water for a period of time and can be determined using equation (2).

$$
\text { Swell }=\left[V_{2}-V_{1}\right]
$$

Where;

$\mathrm{V}_{1}=$ volume before immersion

$\mathrm{V}_{2}=$ volume after immersion

Swelling index can simply be defined as the percentage increase in the volume of asphalt concrete as a result of absorption of water when submerged in water. Swelling in asphalt concrete pavement can be achieved using an index called swelling index. And it can be evaluated using equation (3)

Where;

$\mathrm{V} 1$ = Volume of HMA concrete specimen before immersion;

$\mathrm{V} 2$ = Volume of HMA concrete specimen after immersion

$$
S I=\left[\frac{V_{2}-V_{1}}{V_{1}}\right] \times 100
$$

\section{RESULTS AND DISCUSSIONS}

\subsection{Classification Tests and Aggregate Mix Proportion}

Results of the classification test of materials are as presented in Table 1 while the schedule of aggregates used for mix proportion in accordance with [6] is presented in Table 2

Table1. Properties of Materials and Classification Test

\begin{tabular}{|c|c|c|c|c|c|}
\hline & \multicolumn{5}{|c|}{ Materials } \\
\hline Tests & Bitumen & Gravel & Sand & Bamboo Ash & Asphalt Concrete \\
\hline Specific gravity (G) & 1.03 & 2.73 & 2.8 & 1.86 & - \\
\hline Penetration Grade (mm) & 59 & - & - & - & - \\
\hline Viscosity (Secs) & 13.4 & - & - & - & - \\
\hline $\begin{array}{c}\text { Softening Point of } \\
\text { Bitumen. }\left({ }^{\circ} \mathrm{C}\right)\end{array}$ & 48 & - & - & - & - \\
\hline $\begin{array}{c}\text { Mix Proportion Used } \\
(\%)\end{array}$ & - & 59 & 41 & - & HEAVY \\
\hline Category of Traffic & - & - & - & - & - \\
\hline
\end{tabular}

Table2. Schedule of Aggregates Used For Mix Proportion in Accordance With ASTM 2001: C136

\begin{tabular}{|c|c|c|c|c|c|}
\hline $\begin{array}{c}\text { Sieve Size } \\
\text { (inch) }\end{array}$ & $\begin{array}{c}\text { Sieve size } \\
(\mathbf{m m})\end{array}$ & Specification limit & $\begin{array}{c}\text { Aggregate A } \\
\text { (Gravel) }\end{array}$ & Aggregate B (Sand) & $\begin{array}{c}\text { Mix proportion } \\
(\mathbf{0 . 5 9 A}+\mathbf{0 . 4 1 B})\end{array}$ \\
\hline $3 / 4$ & 19 & 100 & 99.1 & 100 & 99.45 \\
\hline $1 / 2$ & 12.5 & $86-100$ & 86.1 & 100 & 91.8 \\
\hline $3 / 8$ & 9.5 & $70-90$ & 57.5 & 100 & 74.93 \\
\hline $1 / 4$ & 6.3 & $45-70$ & 21.8 & 100 & 53.86 \\
\hline No. 4 & 4.75 & $40-60$ & 7.5 & 99.5 & 45.22 \\
\hline No. 8 & 2.36 & $30-52$ & 3.5 & 97.3 & 41.96 \\
\hline No. 16 & 1.18 & $22-40$ & 2.3 & 92.3 & 39.2 \\
\hline No. 30 & 0.6 & $16-30$ & 1.8 & 69 & 29.3 \\
\hline No. 50 & 0.3 & $9-19$ & 1.4 & 28.2 & 12.39 \\
\hline No. 100 & 0.15 & $3-7$ & 1 & 8.4 & 4 \\
\hline No. 200 & 0.075 & 0 & 0.6 & 0.8 & 0.68 \\
\hline
\end{tabular}




\subsection{Marshall Stability}

The result of Marshall Stability of the compacted specimens at various filler (modifier) contents are as presented in Table 3 and Figure 1. From Figure 1, the results showed that for dry (unsoaked) specimens, on addition of Bamboo Ash, Stability increased from $12473 \mathrm{~N}$ at $0 \%$ modifier content to an optimum of $14900 \mathrm{~N}$ at $3 \%$ modifier content and on further addition of the filler, Stability decreased to $10080 \mathrm{~N}$ at $5 \%$ modifier content. This result indicated that addition of Bamboo Ash (BA) improved the Stability of asphalt concrete with an optimum result achieved at $3 \%$ modifier content.

For the soaked specimen (day 1), Stability increased from $10544 \mathrm{~N}$ at $0 \%$ modifier content to an optimum value of $14430 \mathrm{~N}$ at $3 \%$ modifier content and decreased to $9300 \mathrm{~N}$ at $5 \%$ modifier content. The same trend was shown for days 2, 3, 4 and 5. The study also showed that the stability of Asphalt Concrete modified with BA decreased as the number of days of submergence increased, however, the results are within acceptable limits as stipulated by Asphalt Institute Criteria for Marshall Mix Design [9].

Table3. Marshall Stability of Bamboo Ash-Modified Asphalt Concrete

\begin{tabular}{|c|c|c|c|c|c|c|}
\hline \multicolumn{7}{|c|}{ Marshall Stability (N) for Modified Concretes and Immersion Days } \\
\hline \multirow{2}{*}{$\begin{array}{c}\text { Modifier } \\
\text { Content (\%) }\end{array}$} & $\mathbf{0}$ & $\mathbf{1}$ & $\mathbf{2}$ & $\mathbf{3}$ & $\mathbf{4}$ & $\mathbf{5}$ \\
\cline { 2 - 7 } & $\mathbf{0}$ & 10544 & 9803 & 8606 & 8306 & 8008 \\
\hline 0 & 12473 & 12240 & 11140 & 10100 & 9110 & 8810 \\
\hline 1 & 12980 & 13210 & 11960 & 10650 & 9380 & 9001 \\
\hline 2 & 13420 & 14430 & 13220 & 11980 & 10900 & 10290 \\
\hline 3 & 14900 & 11100 & 10090 & 9340 & 8676 & 8080 \\
\hline 4 & 11790 & 9300 & 8465 & 7760 & 7320 & 6690 \\
\hline 5 & 10080 & & &
\end{tabular}

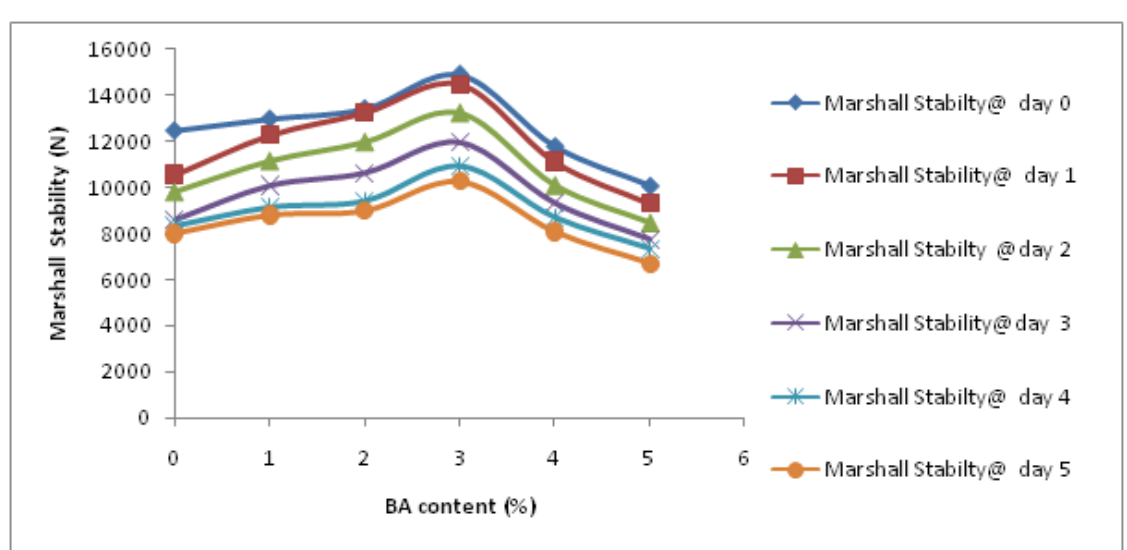

Figure1. Variation of Marshall Stabilit with Bamboo Ash Content

\subsection{Retained Marshall Stability}

The Index of Retained Marshall Stability (RMS) of the modified and unmodified asphalt concrete under submerged conditions for a period of 0 to 5 days are presented in Table 4 while the influence of Bamboo Ash as filler on RMS is shown in Figure 2. RMS measures the resistance to moisture damage of asphalt concrete mixtures. For day 1, Figure 2 showed that the index of RMS under submerged conditions increased with addition of BA from $84.53 \%$ at $0 \%$ modifier content to an optimum of $96.44 \%$ at $3 \%$ modifier content. The trend was repeated for days 2, 3, 4 and 5 . The result implied that the addition of Bamboo Ash reduced loss in Stability by increasing the RMS hence, increasing resistance to moisture damage of the material between 0\% - 3\% Bamboo Ash content.

Table4. Retained Marshall Stability of Bamboo Ash Modified Asphalt Concrete

\begin{tabular}{|r|c|c|c|c|c|c|}
\hline \multicolumn{6}{|c|}{ Retained Marshall Stability (\%) for Modified Concretes and Immersion Days (\%) } \\
\hline $\begin{array}{c}\text { Modifier } \\
\text { Content (\%) }\end{array}$ & $\mathbf{0}$ & $\mathbf{1}$ & $\mathbf{2}$ & $\mathbf{3}$ & $\mathbf{4}$ & $\mathbf{5}$ \\
\cline { 2 - 7 } & $\mathbf{0}$ & 84.53 & 78.36 & 69 & 66.45 & 63.9 \\
\hline 0 & 100 & 86.83 & 80.88 & 77.81 & 65.7 & 64.29 \\
\hline 1 & 100 & 89.93 & 83.59 & 79.22 & 66.85 & 67.05 \\
\hline 2 & 100 & 96.44 & 93.12 & 83.34 & 76.59 & 74.2 \\
\hline 3 & 100 & 94.42 & 86.66 & 80.4 & 71.65 & 68.19 \\
\hline 4 & 100 & 89.69 & 80.93 & 77.36 & 70.25 & 62.43 \\
\hline 5 & 100 & & &
\end{tabular}




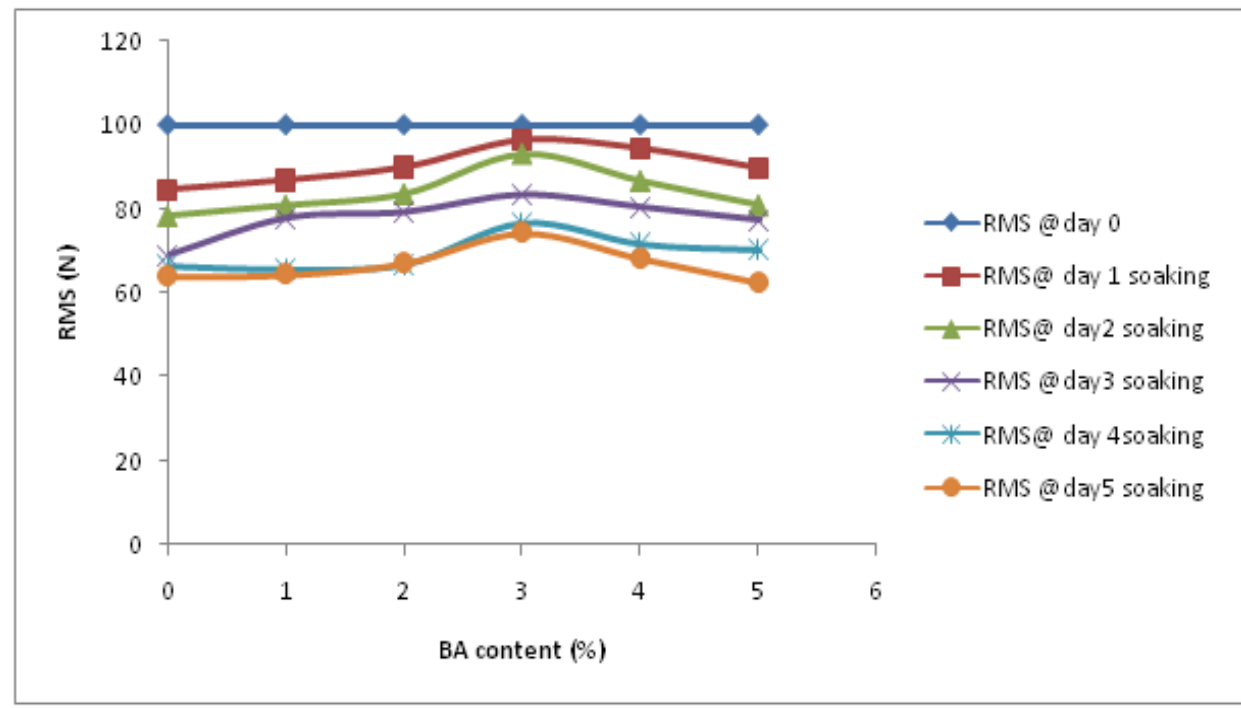

Figure2. Variation of Retained Marshall Stability with Bamboo Ash content

\subsection{Swell}

The result of Swell which represents the increase in volume as a result of absorption of water by the modified and unmodified asphalt concrete specimen when submerged in water for a period of $0-5$ days is a presented in Table 5 and Figure 3.

Table5. Swell of Bamboo Ash-Modified Asphalt Concrete

\begin{tabular}{|c|c|c|c|c|c|c|}
\hline \multicolumn{7}{|c|}{ Marshall Stability (N) for Modified Concretes and Immersion Days } \\
\hline $\begin{array}{c}\text { Modifier } \\
\text { Content (\%) }\end{array}$ & $\mathbf{0}$ & $\mathbf{1}$ & $\mathbf{2}$ & $\mathbf{3}$ & $\mathbf{4}$ & $\mathbf{5}$ \\
\cline { 2 - 7 } & 12473 & 10544 & 9803 & 8606 & 8306 & 8008 \\
\hline 0 & 12980 & 12240 & 11140 & 10100 & 9110 & 8810 \\
\hline 1 & 13420 & 13210 & 11960 & 10650 & 9380 & 9001 \\
\hline 2 & 14900 & 14430 & 13220 & 11980 & 10900 & 10290 \\
\hline 3 & 11790 & 11100 & 10090 & 9340 & 8676 & 8080 \\
\hline 4 & 10080 & 9300 & 8465 & 7760 & 7320 & 6690 \\
\hline 5 & & & & & \\
\hline
\end{tabular}

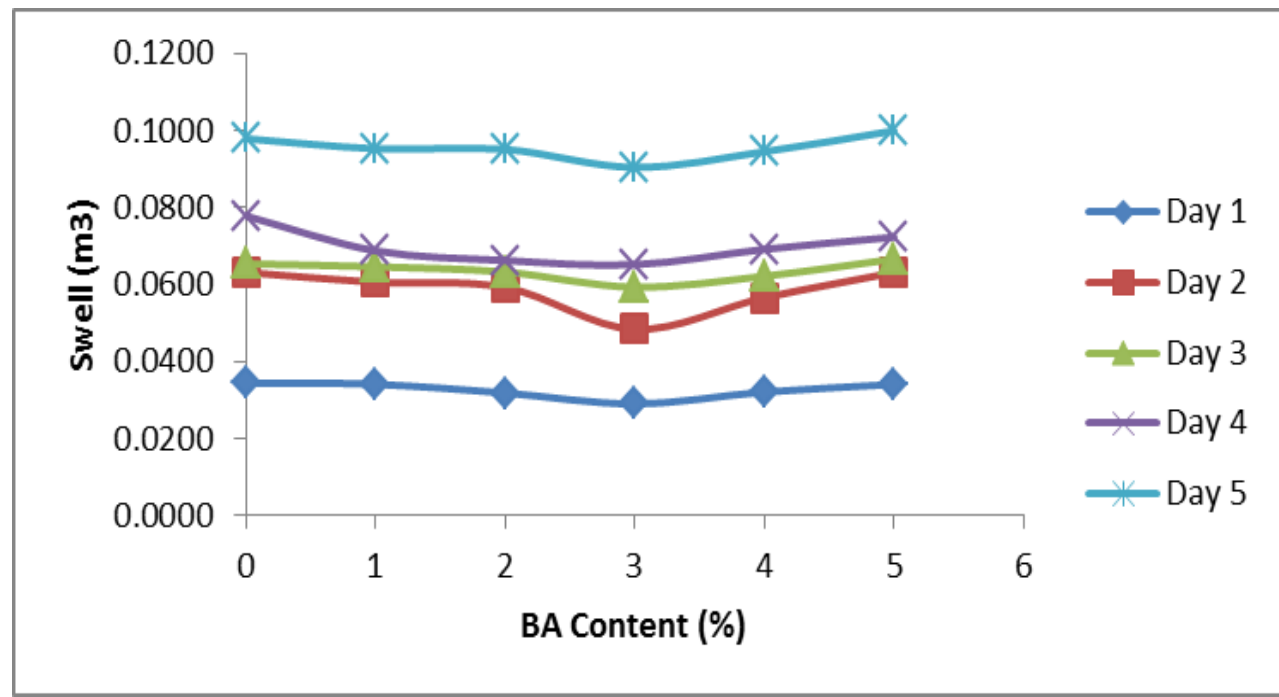

Figure3. Variation of Swell with Bamboo Ash content

\subsection{Swelling Index}

The result of the reduction in Swell measured using Swelling Index (SI) is as presented in Table 6, while the variation of Swelling Index with Bamboo Ash content is shown in Figure 4. The results showed a reduction in swell between 0-3\% Bamboo Ash content with SI of 1.19\% at Day 1, 1.99\% at Day 2, 2.40\% at Day 3, 2.58\% at Day 4 and 3.56\% at Day 5. The results also showed that SI of asphalt concrete modified with BA increased as the number of days of submergence increased. 
Table6. Swelling Index of Bamboo Ash modified Asphalt Concrete

\begin{tabular}{|c|c|c|c|c|c|}
\hline \multicolumn{6}{|c|}{ Swelling Index (\%) for modified concretes and Immersion days } \\
\hline \multirow{4}{*}{$\begin{array}{l}\text { Modifier } \\
\text { Content }(\%)\end{array}$} & \multicolumn{5}{|c|}{ Swelling Index SI $(\%)=($ V2-V1 $) / V 1 * 100$} \\
\hline & \multicolumn{5}{|c|}{ Immersion Days } \\
\hline & Day 1 & Day 2 & Day 3 & Day 4 & Day 5 \\
\hline & B.A & B.A & B.A & B.A & B.A \\
\hline 0 & 1.50 & 2.75 & 2.80 & 3.28 & 4.04 \\
\hline 1 & 1.46 & 2.59 & 2.72 & 2.84 & 3.88 \\
\hline 2 & 1.34 & 2.51 & 2.65 & 2.71 & 3.81 \\
\hline 3 & 1.19 & 1.99 & 2.40 & 2.58 & 3.56 \\
\hline 4 & 1.28 & 2.26 & 2.47 & 2.69 & 3.64 \\
\hline 5 & 1.33 & 2.44 & 2.51 & 2.68 & 3.70 \\
\hline
\end{tabular}

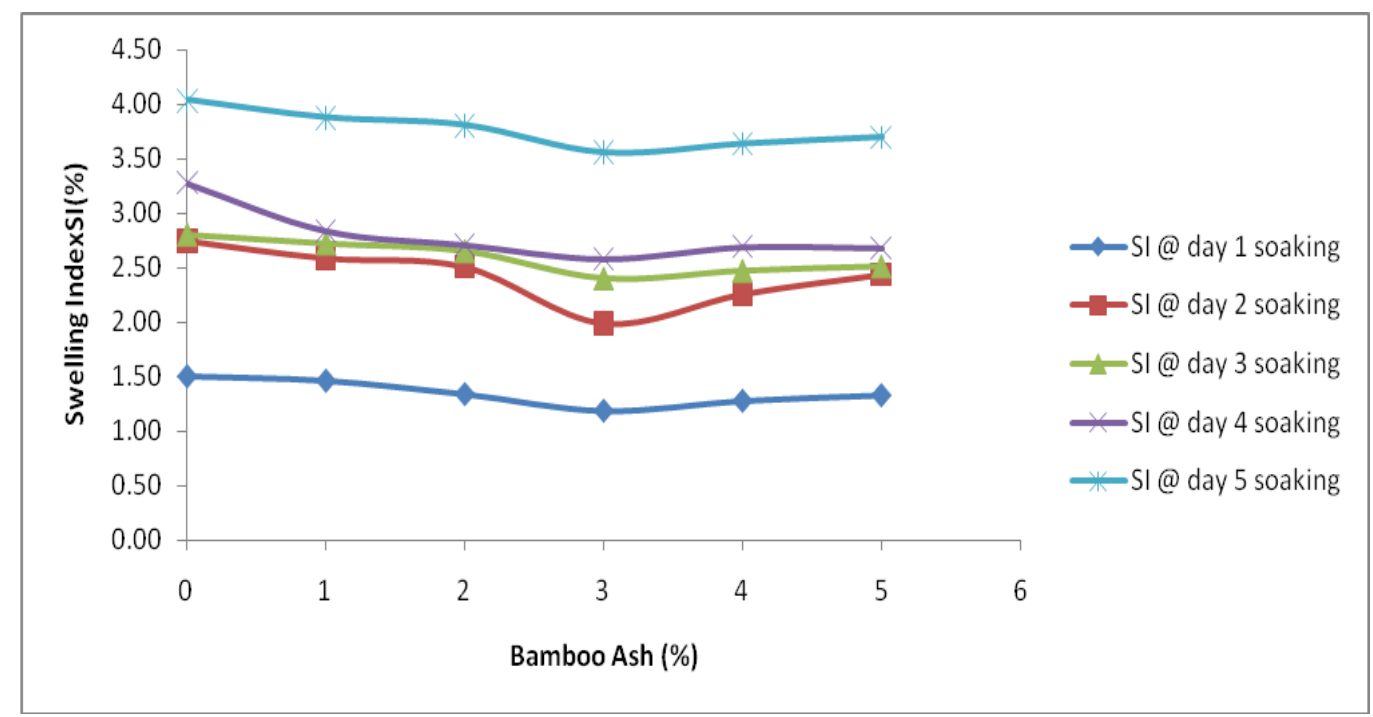

Figure4. Variation of Swelling Index with BA content

\section{CONCLuSion}

On the basis of experimental results of the investigation of the effect of Bamboo Ash as void filler on Retained Marshal Stability and Swelling Index of asphalt concrete mixtures, the following conclusions were drawn:

- The performance of asphalt concrete mixes with Bamboo Ash as filler is good in terms of resistance to moisture damage.

- The addition of Bamboo Ash to asphalt concrete up to 3\% reduced the amount of Swell in the concrete when submerged.

- From the study, Bamboo Ash recorded best result at 3\% optimum modifier content.

Bamboo Ash can serve as a good material for the modification of asphalt concrete and should be recommended for use in asphalt concrete production.

\section{REFERENCE}

[1] Ajayi, L. A., Thoughts on Road Failures in Nigeria" The Nigerian Engineer, 22(1) pp. 10-17 (1987).

[2] Chapuis R.P. and Legare P. P., "A Simple Method for Determining the Surface Area of Fine Aggregates and Fillers in Bituminous Mixtures, Effect of Aggregates and Mineral Fillers on Asphalt Mixtures Performance" ASTM STP 1147, Richard C. Meininger, Ed., American Society for Testing and Material, Philadelphia, 1992.

[3] Kim Y. R., Kim N. and Khosla N. P., "Effects of Aggregate Type and Gradation on Fatigue and Permanent Deformation of Asphalt Concrete, Effect of Aggregates and Mineral Fillers on asphalt Mixtures Performance", ASTM STP 1147, Richard C. Meininger, Ed., American Society for Testing and Material, Philadelphia, 1992.

[4] Shuler T. S. and Huber G., "Effect of Aggregate Size and Other Factors on Refusal Density of Asphalt Concrete by Vibratory Compaction, Effect of Aggregates and Mineral Fillers on asphalt Mixtures 
Performance" ASTM STP 1147, Richard C. Meininger, Ed., American Society for Testing and Material, Philadelphia, 1992.

[5] Roberts F. L. Kandhal P. S., Brown E. R., Lee,D. Y. and Kennedy,T. W, "Hot Mix Asphalt Materials, Mixture Design, and Construction" National Asphalt Pavement Association Education Foundation Lanham, MD. 1996.

[6] ASTM C136, "Standard Test Method for Sieve Analysis of Fine and Coarse Aggregate" ASTM International, West Conshohocken, PA, 2001.

[7] ASTM D 1559 - 76, "Standard Test Method for Resistance to Plastic Flow of Bituminous Mixtures Using Marshall Apparatus”. ASTM International, West Conshohocken, PA, 2004.

[8] Putra A. M., and Suparma L. B., Laboratory Study on the Durability Characteristics (Moisture Damage Evaluation) of Asphalt Concrete Wearing Course (AC-WC) Utilizing Bantak and Clerang as Aggregate (using Marshal Methods) Proceedings of the Eastern Asia Society for Transportation Studies, 2009.

[9] Asphalt Institute, "Mix Design Methods for Asphalt," 6 ${ }^{\text {th }}$ edition MS-02. Asphalt Institute, Lexington, 2001.

Citation: Gloria G. George, et.al (2021). “Improving Resistance to Moisture Damage of Asphalt Concrete Using Bamboo Ash as Void Filler". International Journal of Constructive Research in Civil Engineering (IJCRCE), vol. 7, no. 1, pp. 1-7, 2021. Available: DOI: https:// doi.org/10.20431/2454-8693.0701001

Copyright: (C) 2021 Authors. This is an open-access article distributed under the terms of the Creative Commons Attribution License, which permits unrestricted use, distribution, and reproduction in any medium, provided the original author and source are credited. 